\title{
Treatment Persistence and Adherence Among Patients With Psoriatic Arthritis Who Initiated Targeted Immune Modulators in the US: A Retrospective Cohort Study
}

Jessica A. Walsh • Qian Cai · Iris Lin · Christopher D. Pericone ·

Soumya D. Chakravarty

Received: January 7, 2021 / Accepted: February 25, 2021 / Published online: March 23, 2021

(C) The Author(s) 2021

\section{ABSTRACT}

Introduction: This study compared treatment persistence and adherence among psoriatic arthritis (PsA) patients in the US who initiated an interleukin-12/23 inhibitor (IL-12/23i) versus those who initiated tumor necrosis factor inhibitors (TNFis), targeted synthetic diseasemodifying antirheumatic drugs (tsDMARDs), or interleukin-17 inhibitors (IL-17is).

Methods: Adults diagnosed with PsA with $\geq 1$ claim for a targeted immune modulator were selected from the IBM MarketScan ${ }^{\circledR}$ Commercial and Medicare Supplemental databases (October 1, 2013-October 31, 2018). The date of

Supplementary Information The online version contains supplementary material available at https:// doi.org/10.1007/s12325-021-01687-w.

J. A. Walsh ( $\square)$

University of Utah School of Medicine and Salt Lake City Veterans Affairs Medical Center, Salt Lake City, UT, USA

e-mail: Jessica.Walsh@hsc.utah.edu

Q. Cai · C. D. Pericone

Janssen Scientific Affairs, LLC, Real World Value and Evidence, Titusville, NJ, USA

I. Lin · S. D. Chakravarty

Janssen Scientific Affairs, LLC, Immunology Medical

Affairs, Horsham, PA, USA

S. D. Chakravarty

College of Medicine, Drexel University,

Philadelphia, PA, USA the first claim was the index date. Patients had continuous health plan enrollment for $\geq 12$ months pre-index and $\geq 12$-month post-index period. Pairwise propensity score matching with nearest-neighbor technique was performed. Persistence duration, discontinuation rate, and the proportion of days covered (PDC) were evaluated in biologic/tsDMARD naïve patients who initiated TNFis, IL-17is, tsDMARDs, or IL-12/23i (reference group).

Results: There were 238 matched patient pairs for TNFi versus IL-12/23i, 238 pairs for tsDMARD versus IL-12/23i, and 189 pairs for IL17 is versus IL-12/23i. Duration of persistence was longer for the IL-12/23i cohort than for the TNFi (269 vs. 215 days, $p<0.001$ ) or tsDMARD (269 vs. 213 days, $p<0.001$ ) cohorts, but comparable between the IL-12/23i and IL-17i cohorts (267 vs. 246 days, $p=0.199$ ). Fewer patients in the IL-12/23i cohort discontinued their index medication than in the TNFi $(53.4 \%$ vs. $73.9 \%, p<0.001)$ or tsDMARD $(53.4 \%$ vs. $71.8 \%, p<0.001)$ cohorts, but no significant difference was observed between the IL-12/23i and IL-17i cohorts $(52.9 \%$ vs. $58.2 \%, p=0.288)$. During the 12-month follow-up, adherence (i.e., PDC) was higher among those who initiated an IL-12/23i than among those who initiated TNFis $(0.64$ vs. $0.56, p=0.004)$ or tsDMARDs (0.64 vs. $0.58, p=0.027)$, but similar to those who initiated IL-17is (0.64 vs. 0.65, $p=0.589)$. 
Conclusion: In this real-world study of PsA therapies with differing mechanisms of action, the IL-12/23i demonstrated longer persistence and higher adherence than either TNFis or tsDMARDs, and comparability to IL-17is.

Keywords: Adherence; Psoriatic arthritis; Interleukin-12/23 inhibitor; Interleukin-17 inhibitors; Persistence; Targeted immune modulators; Targeted synthetic diseasemodifying antirheumatic drugs; Tumor necrosis factor inhibitors

\section{Key Summary Points}

Why carry out this study?

With the array of medications available to treat psoriatic arthritis (PsA), treatment patterns in real-world settings can provide insight into patient experience with medications and help the provider determine appropriate treatment based on patient and disease characteristics.

This study compared treatment persistence and adherence among PsA patients in the US who initiated an interleukin-12/23 inhibitor (IL-12/23i) versus those who initiated tumor necrosis factor inhibitors (TNFis), targeted synthetic disease-modifying antirheumatic drugs (tsDMARDs), or interleukin-17 inhibitors (IL-17is).

\section{What was learned from the study?}

In this real-world study of PsA therapies with differing mechanisms of action, patients who initiated an IL-12/23i had longer persistence, a lower discontinuation rate, and higher adherence compared to those who initiated a TNFi or tsDMARD during 1 year of follow-up.

Persistence duration, discontinuation rates, and adherence were similar in patients who initiated an IL-12/23i versus an IL-17i.

\section{DIGITAL FEATURES}

This article is published with digital features, including a summary slide, to facilitate understanding of the article. To view digital features for this article go to https://doi.org/10.6084/ m9.figshare.14096311.

\section{INTRODUCTION}

Psoriatic arthritis (PsA) is a chronic, immunemediated inflammatory disease characterized by peripheral and axial joint inflammation, enthesitis, and dactylitis; it can be frequently accompanied by psoriatic skin and nail lesions $[1,2]$. PsA can manifest from mild joint stiffness and swelling to severe joint destruction leading to long-term functional disability $[1,2]$. In the United States, the prevalence of PsA has been estimated at $0.05-0.25 \%$ [3]. A recently published meta-analysis, which included over 950,000 patients, reported the proportion of patients with PsA among those with psoriasis is $20 \%$ and, among those with moderate to severe psoriasis, it is $25 \%$ [4].

Multiple biologic therapies have shown efficacy for the treatment of PsA and have been approved by the US Food \& Drug Administration (FDA), including the tumor necrosis factor inhibitors (TNFis), adalimumab, certolizumab pegol, etanercept, golimumab, and infliximab; the interleukin-12/23 inhibitor (IL-12/23i), ustekinumab; and the interleukin-17 inhibitors (IL-17is), secukinumab and ixekizumab. In addition, oral targeted synthetic disease-modifying antirheumatic drugs (tsDMARDs), such as apremilast and tofacitinib, have emerged as alternatives to conventional synthetic DMARDs (csDMARDs). The 2018 American College of Rheumatology/National Psoriasis Foundation Guideline for the treatment of PsA recommends using a TNFi as first-line therapy for treatmentnaïve patients instead of oral small-molecule drugs, unless TNFis are contra-indicated, the patient prefers an oral medication, or is concerned about specific side effects [2]. These guidelines also recommend initiating an IL-17i 
or an IL-12/23i if TNFis are contra-indicated or for certain domains of PsA [2].

With the array of medications available for the treatment of PsA, studies are needed to examine the treatment patterns of medications with varying mechanisms of action (MOA) among patients with PsA in real-world settings. In an administrative claims database analysis, Feldman et al. reported that, among PsA patients who initiated apremilast versus those who initiated biologics (adalimumab, certolizumab, etanercept, golimumab, infliximab, secukinumab, or ustekinumab), treatment adherence and persistence were similar 12 months post-initiation [5]. However, biologic therapies used to treat PsA target specific types of immune cells or proteins and treatment patterns may differ according to the MOA. In this study, we compared treatment persistence and adherence among PsA patients in the US who initiated an IL-12/23i versus those who initiated TNFis, tsDMARDs or IL-17is.

\section{METHODS}

\section{Study Design and Data Source}

This was a retrospective observational cohort study that used administrative medical and pharmacy claims data obtained from the IBM MarketScan ${ }^{\circledR}$ Commercial and Medicare Supplemental databases between October 1, 2012 and October 31, 2018. The MarketScan Commercial database contains healthcare claims of employees and their dependents, while the MarketScan Medicare Supplemental database contains the healthcare claims of individuals with Medicare supplemental insurance paid for by employers. Both databases provide information about enrollment data and healthcare services performed in inpatient and outpatient medical service, as well as outpatient pharmacy settings. Data records are de-identified and certified to be fully compliant with the Health Insurance Portability and Accountability Act patient confidentiality requirements. Institutional review board approval to conduct this study was not required because the study used only de-identified patient records and did not involve the collection, use, or transmittal of individually identifiable data.

\section{Patient Selection Criteria}

Patients with $\geq 1$ medical or pharmacy claim for a targeted immune modulator (TNFis: adalimumab, certolizumab pegol, etanercept, golimumab, infliximab; tsDMARDs: apremilast, tofacitinib; IL-17is-secukinumab, ixekizumab; or the IL-12/23i: ustekinumab) from October 1, 2013 through October 31, 2018 were selected from the MarketScan databases. The date of the first medical or pharmacy claim was designated as the index date. To increase the specificity of patient identification, patients were required to have $\geq 2$ medical claims with PsA diagnoses (ICD-9-CM: 696.0; ICD-10-CM: L40.50-L40.54, L40.59) that occurred $\geq 30$ days apart from 12 months pre-index to 12 months post-index period, with the first diagnosis having occurred on or prior to the index date. Patients were also required to be $\geq 18$ years of age on the index date and to have continuous health plan enrollment for $\geq 12$ months pre-index and during the $\geq 12$-month post-index period (follow-up period). To ensure patients were biologic/tsDMARD naïve, those who had $\geq 2$ different targeted immune modulators on the index date or used any of the study medications any time prior to the index date were excluded. Patients were also excluded if during the 12-month pre-index period they had a medical claim for ulcerative colitis, Crohn's disease, rheumatoid arthritis, ankylosing spondylitis, other spondyloarthropathies, or any comorbidity contra-indicated per the prescribing information for their specific index medication.

Patients were grouped into 4 study cohorts based on their index medication class: TNFi, tsDMARD, IL-17i, or IL-12/23i. To increase comparability of study cohorts and to reduce potential confounding biases due to differences in baseline characteristics, pairwise propensity score matching with nearest-neighbor technique was performed to compare patients who initiated TNFis, tsDMARDs, or IL-17is to those who initiated the IL-12/23i (reference group). Propensity scores were calculated using 
multivariable logistic regression with covariates (identified a priori), including age, gender, region, insurance type, health plan type, Quan-Charlson Comorbidity Index score (QCI), and usage of conventional synthetic DMARDs (csDMARDs) [6] and non-steroidal anti-inflammatory drug (NSAIDs). To evaluate balance in the measured variables between matched cohorts, standardized differences $(|\mathrm{d}|)$ were used with $|d|>0.2$ being considered as an imbalance.

\section{Outcome Measures}

During the 12-month follow-up period, duration of persistence, discontinuation rate, and adherence with index medication were evaluated and compared between matched cohorts. Days' supply data were directly available from pharmacy claims for each index medication. In contrast, days' supply data are not available in medical claims; therefore days' supply was estimated for medical claims medications, based on FDA-approved dosing schedules. For instance, the recommended dosing for ustekinumab is 4 weeks after induction, followed every 12 weeks. If the index claim for ustekinumab was a medical claim, a value of 28 was assigned as days' supply for the index fill, and days' supply of 84 was assigned for subsequent fills. During the 12-month follow up period, there were 2561 medical and pharmacy claims of TNFi or IL-12/23i, of which $8.9 \%$ were from medical claims with estimated days' supply. No specific Healthcare Common procedure Coding System (HCPCS) code is available for IL-17is and HCPCS codes do not apply to oral medications such as tsDMARDs; therefore, no imputation was performed for these two cohorts.

Persistence was measured as the number of days from the index date to the discontinuation date of the index medication or to the end date of the 12-month follow-up, whichever was earlier. There is no uniform definition for the appropriate length of permissible gap over multiple refill intervals; thus, definitions on discontinuation have varied across studies. Since the maintenance dosing interval varies across biologics, a variable length permissible gap was used [7]. Discontinuation of index medications was defined as having a gap in therapy of $\geq 1.5$ times the maintenance days' supply (i.e., the most frequently observed days' supply) of the index medication, measuring from the end of days' supply of one fill to the date of next fill. Discontinuation date of the index medication was designated as the fill date plus days' supply of the last prescription filled prior to the gap in therapy. Adherence was measured by the proportion of days covered (PDC), which was computed as the sum of nonoverlapping days' supply of index biologic medication during the follow up period divided by 365 days.

\section{Sensitivity Analyses}

To better understand how outcomes differ using different permissible gaps two sensitivity analyses were conducted. One used an allowable gap of 1 times maintenance days' supply of the index medication from the end of days' supply of one fill to the date of next fill, and the other used a fixed allowable gap of 90 days from the end of days' supply of one fill to the date of the next fill for all the targeted immune modulators.

\section{Statistical Analyses}

For descriptive analyses, mean and standard deviations (SD) were reported for continuous variables whereas frequency and percentage were reported for categorical variables. Kaplan-Meier curves were generated to display duration of persistence and log-rank tests were used to evaluate the different in duration distribution of compared cohorts. To test the statistical difference in discontinuation rate, conditional logistic regression was performed, and for PDC, paired $t$ tests were used. A $p$ value of $<0.05$ was considered statistically significant. All data analyses were conducted using SAS Enterprise Guide 7 (SAS Institute, Cary, NC, USA). 


\section{RESULTS}

\section{Patient Characteristics}

A total of 7,205 patients with PsA who newly initiated a targeted immune modulator met the study selection criteria (Fig. 1). Demographic and clinical characteristics of patients prior to pairwise PS matching are shown in Table S1. After matching, there were 238 matched patient pairs in the IL-12/23i versus TNFi cohorts, 238 patient pairs for IL-12/23i versus tsDMARD cohorts, and 189 patient pairs for IL-12/23i versus IL-17i cohorts.

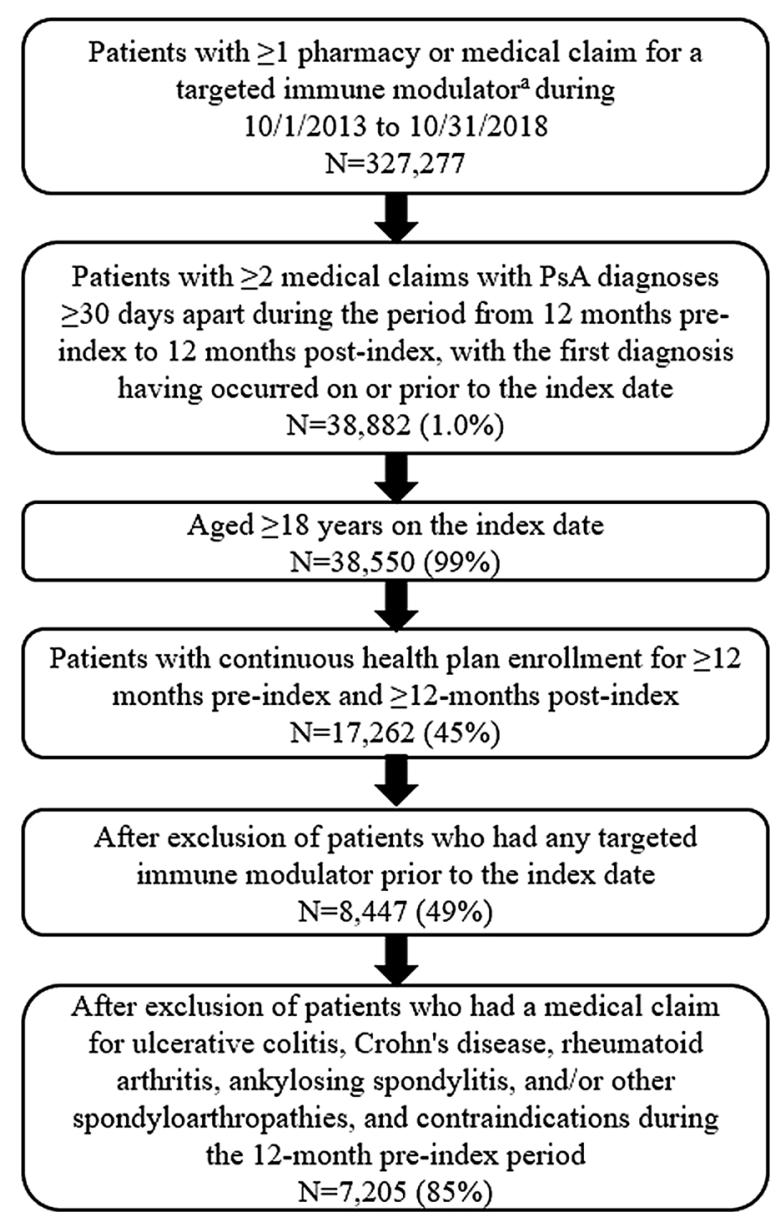

Fig. 1 Patient selection process. ${ }^{\text {a }}$ Targeted immune modulators: Adalimumab, certolizumab pegol, etanercept, golimumab, infliximab, apremilast, tofacitinib, secukinumab, ixekizumab, ustekinumab
Overall, matched cohorts were well balanced on baseline demographic and clinical characteristics (Table 1). Mean ages of the matched patient cohorts ranged from 49.2 to 51.7 years and $50.8-57.1 \%$ were female. A majority of study patients had commercial insurance $(>88 \%)$ and preferred provider organization (PPO) health plans (>59\%). Mean QCI scores ranged from 0.4 to 0.6. Approximately onethird of patients had usage of csDMARDs, and nearly one-half had usage of NSAIDs prior to initiating targeted immune modulators.

\section{Persistence and Adherence}

At 12 months post-index, mean duration of persistence was significantly longer among PsA patients who initiated an IL-12/23i than among those who initiated TNFis (269 vs. 215 days, $p<0.001)$ or tsDMARDs (269 vs. 213 days, $p<0.001)$; treatment persistence was not significantly different between the IL-12/23i and IL-17i cohorts (267 vs. 246 days, $p=0.199$ ) (Table 2; Fig. 2). Significantly more PsA patients who initiated an IL-12/23i than among those who initiated TNFis $(86.1 \%$ vs. $70.2 \%$, $p<0.001)$, or tsDMARDs $(86.1 \%$ vs. $74.4 \%$, $p=0.002)$, or IL-17is $(85.7 \%$ vs. $77.2 \%$, $p=0.048)$ persisted with their index medication for $\geq 90$ days (Table 2).

During the 12-month follow-up, the IL-12/ 23i cohort had fewer patients who discontinued their index medication than the TNFi cohort $(53.4 \%$ vs. $73.9 \%, p<0.001)$ or tsDMARD cohort (53.4\% vs. $71.8 \%, p<0.001)$; discontinuation rates did not significantly differ between the IL-12/23i and IL-17i cohorts $(52.9 \%$ vs. $58.2 \%, p=0.288$ ) (Table 2).

During the 12-month follow-up period, the mean PDC was significantly higher among patients who initiated an IL-12/23i than among those who initiated TNFis (0.64 vs. 0.56, $p=0.004)$ or tsDMARDs (0.64 vs. 0.58, $p=0.027)$; adherence was not statistically different between patients who initiated an IL-12/ 23i and IL-17is (0.64 vs.. 0.65, $p=0.589)$ (Fig. 3). 
Table 1 Demographic and clinical characteristics of matched study cohorts ${ }^{\mathrm{a}}$

\begin{tabular}{|c|c|c|c|c|c|c|c|c|c|}
\hline Variable & $\begin{array}{l}\text { IL-12/23i, } \\
N=238\end{array}$ & $\begin{array}{l}\text { TNFi, } \\
N=238\end{array}$ & $|\mathbf{d}|^{\mathbf{b}}$ & $\begin{array}{l}\text { IL-12/23i, } \\
N=238\end{array}$ & $\begin{array}{l}\text { tsDMARD, } \\
N=238\end{array}$ & $|\mathbf{d}|^{\mathbf{b}}$ & $\begin{array}{l}\text { IL-12/23i, } \\
N=189\end{array}$ & $\begin{array}{l}\text { IL-17i, } \\
N=189\end{array}$ & $|\mathbf{d}|^{\mathbf{b}}$ \\
\hline $\begin{array}{l}\text { Age at index } \\
(\text { mean, SD) }\end{array}$ & $50.8(12.6)$ & $50.9(12.5)$ & 0.001 & $50.8(12.6)$ & $51.7(12.3)$ & 0.068 & $50.8(12.5)$ & $49.2(11.3)$ & 0.133 \\
\hline \multicolumn{10}{|l|}{ Gender $(n, \%)$} \\
\hline Male & $115(48.3)$ & $110(46.2)$ & 0.042 & $115(48.3)$ & $116(48.7)$ & 0.008 & $93(49.2)$ & $81(42.9)$ & 0.128 \\
\hline Female & $123(51.7)$ & $128(53.8)$ & 0.042 & $123(51.7)$ & $122(51.3)$ & 0.008 & $96(50.8)$ & $108(57.1)$ & 0.128 \\
\hline \multicolumn{10}{|c|}{ US geographic region, $n(\%)$} \\
\hline Northeast & $57(23.9)$ & $55(23.1)$ & 0.020 & $57(23.9)$ & $64(26.9)$ & 0.068 & $49(25.9)$ & $44(23.3)$ & 0.061 \\
\hline Midwest & $32(13.4)$ & $32(13.4)$ & 0.000 & $32(13.4)$ & $27(11.3)$ & 0.064 & $29(15.3)$ & $33(17.5)$ & 0.057 \\
\hline South & $118(49.6)$ & $121(50.8)$ & 0.025 & $118(49.6)$ & $121(50.8)$ & 0.025 & $83(43.9)$ & $85(45.0)$ & 0.021 \\
\hline West & $31(13.0)$ & $30(12.6)$ & 0.013 & $31(13.0)$ & $26(10.9)$ & 0.065 & $28(14.8)$ & $27(14.3)$ & 0.015 \\
\hline \multicolumn{10}{|c|}{ Insurance type, $n(\%)$} \\
\hline Commercial & $211(88.7)$ & $212(89.1)$ & 0.013 & $211(88.7)$ & $213(89.5)$ & 0.027 & $168(88.9)$ & $177(93.7)$ & 0.169 \\
\hline Medicare & $27(11.3)$ & $26(10.9)$ & 0.013 & $27(11.3)$ & $25(10.5)$ & 0.027 & $21(11.1)$ & $12(6.3)$ & 0.169 \\
\hline Supplemental & & & & & & & & & \\
\hline \multicolumn{10}{|c|}{ Health plan type, $\mathrm{n}(\%)$} \\
\hline $\mathrm{PPO}$ & $152(63.9)$ & $157(66.0)$ & 0.044 & $152(63.9)$ & $158(66.4)$ & 0.053 & $117(61.9)$ & $113(59.8)$ & 0.043 \\
\hline $\begin{array}{l}\text { CDHP/ } \\
\text { HDHP }\end{array}$ & $40(16.8)$ & $40(16.8)$ & 0.000 & $40(16.8)$ & $39(16.4)$ & 0.011 & $33(17.5)$ & $39(20.6)$ & 0.081 \\
\hline $\mathrm{HMO}$ & $11(4.6)$ & $9(3.8)$ & 0.042 & $11(4.6)$ & $10(4.2)$ & 0.020 & $11(5.8)$ & $8(4.2)$ & 0.073 \\
\hline Others & $35(14.7)$ & $32(13.4)$ & 0.036 & $35(14.7)$ & $31(13.0)$ & 0.049 & $28(14.8)$ & $29(15.3)$ & 0.015 \\
\hline $\begin{array}{l}\text { QCI, mean } \\
(\mathrm{SD})\end{array}$ & $0.5(1.0)$ & $0.4(0.9)$ & 0.088 & $0.5(1.0)$ & $0.5(0.8)$ & 0.009 & $0.5(1.0)$ & $0.6(1.0)$ & 0.054 \\
\hline \multicolumn{10}{|c|}{ Baseline comorbidities, $\mathrm{n}(\%)$} \\
\hline Hyperlipidemia & $95(39.9)$ & $90(37.8)$ & 0.043 & $95(39.9)$ & $87(36.6)$ & 0.069 & $72(38.1)$ & $58(30.7)$ & 0.156 \\
\hline Hypertension & $102(42.9)$ & $86(36.1)$ & 0.138 & $102(42.9)$ & $102(42.9)$ & 0.000 & $83(43.9)$ & $69(36.5)$ & 0.152 \\
\hline Osteoarthritis & $65(27.3)$ & $75(31.5)$ & 0.298 & $65(27.3)$ & $63(26.5)$ & 0.019 & $47(24.9)$ & $43(22.8)$ & 0.050 \\
\hline $\begin{array}{l}\text { Diabetes (any } \\
\text { type) }\end{array}$ & $42(17.6)$ & $44(18.5)$ & 0.022 & $42(17.6)$ & $35(14.7)$ & 0.080 & $32(16.9)$ & $23(12.2)$ & 0.135 \\
\hline Obesity & $42(17.6)$ & $39(16.4)$ & 0.034 & $42(17.6)$ & $35(14.7)$ & 0.080 & $32(16.9)$ & $44(23.3)$ & 0.159 \\
\hline Uveitis & $1(0.4)$ & $0(0)$ & 0.092 & $1(0.4)$ & $2(0.8)$ & 0.053 & $0(0)$ & $1(0.5)$ & 0.103 \\
\hline $\begin{array}{l}\text { csDMARD } \\
\text { usage, n (\%) }\end{array}$ & $90(37.8)$ & $85(35.7)$ & 0.044 & $90(37.8)$ & $92(38.7)$ & 0.017 & $67(35.4)$ & $67(35.4)$ & 0.000 \\
\hline
\end{tabular}


Table 1 continued

\begin{tabular}{llllllllll}
\hline Variable & IL-12/23i, & TNFi, & $|\mathbf{d}|^{\mathbf{b}}$ & $\begin{array}{l}\text { IL-12/23i, } \\
\boldsymbol{N}=\mathbf{2 3 8}\end{array}$ & $\begin{array}{l}\text { tsDMARD, } \\
\boldsymbol{N}=\mathbf{2 3 8}\end{array}$ & $|\mathbf{d}|^{\mathbf{b}}$ & $\begin{array}{l}\text { IL-12/23i, } \\
\boldsymbol{N}=\mathbf{1 8 9}\end{array}$ & $\begin{array}{l}\text { IL-17i, } \\
\boldsymbol{N}=\mathbf{1 8 9}\end{array}$ & $\left.\left.\right|^{\mathbf{d}}\right|^{\mathbf{b}}$ \\
\hline $\begin{array}{l}\text { NSAID usage, } \\
\text { n(\%) }\end{array}$ & $110(46.2)$ & $120(50.4)$ & 0.084 & $110(46.2)$ & $108(45.4)$ & 0.017 & $87(46.0)$ & $87(46.0)$ & 0.000 \\
\hline
\end{tabular}

$C D H P$ consumer driven health plan, $c S D M A R D$ conventional synthetic disease-modifying antirheumatic drug, $H D H P$ high deductible health plan, $H M O$ health maintenance organization, $I L-12 / 23 i$ interleukin-12/23 inhibitor, $I L-17 i$ interleukin17 inhibitor, NSAID non-steroidal anti-inflammatory drug, PPO preferred provider organization: QCI Quan-Charlson Comorbidity Index score, $S D$ standard deviation, TNFi tumor necrosis factor inhibitor, tsDMARD targeted synthetic disease-modifying antirheumatic drug

a Pairwise propensity score (PS) matching was performed to balance baseline characteristics between study cohorts; multivariable logistic regression was used to calculate the PS, with age, gender, US geographic region, insurance type, health plan type, QCI, csDMARD usage, and NSAID usage as covariates in the models

${ }^{\mathrm{b}}|\mathrm{d}|=$ Standardized difference; difference in means or percentages divided by standard error; $|\mathrm{d}|>0.2$ was considered as an imbalance

\section{Sensitivity Analyses}

When using a variable gap in therapy of 1 times the days of supply of index medications, the treatment outcomes were generally directionally consistent to the default analysis. However, in this sensitivity analysis, the IL-12/23i cohort also had a statistically significant longer mean duration of persistence than the IL-17i cohort (253 vs. 216 days, $p=0.024$ ) (Table 2 ). When using a fixed allowable gap of 90 days for all the targeted immune modulators, the mean duration of persistence remained longer for PsA patients who initiated an IL-12/23i versus a TNFi or tsDMARD, although the latter comparison did not reach statistical significance (Table 2).

\section{DISCUSSION}

In this real-world study of commercially insured patients with PsA, those who initiated an IL-12/ 23i had significantly longer treatment persistence, a lower discontinuation rate, and higher treatment adherence compared to patients who initiated either a TNFi or a tsDMARD during
1 year of follow-up. As expected, the magnitude of difference between medication classes varied according to the definitions of allowable gaps, but the pattern of higher persistence and adherence with IL12/23i than TNFi and tsDMARD was observed throughout both the main analysis and the sensitivity analyses $[8,9]$. Persistence and adherence were similar between IL-12/23 and IL-17i with most outcomes, but a minority of persistence outcomes favored IL-12/ $23 i$.

Although we observed better persistence and adherence among patients with PsA who initiated the IL-12/23i compared to patients who initiated TNFis and tsDMARDs, a little more than half of patients still discontinued their treatment within 1 year. These findings are similar to other studies conducted over the past several years, in which discontinuation rates within 1 year of treatment initiation ranged from $33 \%$ to nearly $70 \%$ among PsA patients treated with biologics or other advanced therapies $[5,6,8,10,11]$. Furthermore, in a study of patients with PsA treated with injectable biologic drugs (adalimumab, certolizumab pegol, etanercept, golimumab, or ustekinumab), the 
Table 2 Treatment persistence during the 12-month follow-up period of matched study cohorts

\begin{tabular}{|c|c|c|c|c|c|c|c|c|c|}
\hline & $\begin{array}{l}\text { IL-12/ } \\
23 \mathrm{i} \\
N=238\end{array}$ & $\begin{array}{l}\text { TNFi, } \\
N=238\end{array}$ & $p$ value & $\begin{array}{l}\text { IL-12/ } \\
23 \mathrm{i} \\
N=238\end{array}$ & $\begin{array}{l}\text { tsDMARD, } \\
N=238\end{array}$ & $p$ value & $\begin{array}{l}\text { IL-12/ } \\
23 \mathrm{i} \\
N=189\end{array}$ & $\begin{array}{l}\text { IL-17i, } \\
N=189\end{array}$ & $p$ value \\
\hline \multicolumn{10}{|l|}{ Main analysis ${ }^{\mathrm{a}}$} \\
\hline $\begin{array}{l}\text { Duration of } \\
\text { persistence in days, } \\
\text { mean (SD) }\end{array}$ & $269(122)$ & $215(133)$ & $<0.001$ & $269(122)$ & $213(131)$ & $<0.001$ & $267(123)$ & $246(133)$ & 0.199 \\
\hline $\begin{array}{l}\text { Persisted } \\
\text { for } \geq 90 \text { days, } \\
n(\%)\end{array}$ & $205(86.1)$ & $167(70.2)$ & $<0.001$ & $205(86.1)$ & $177(74.4)$ & 0.002 & $162(85.7)$ & $146(77.2)$ & 0.048 \\
\hline $\begin{array}{l}\text { Discontinuation of } \\
\text { index medication, } \\
n(\%)\end{array}$ & $127(53.4)$ & $176(73.9)$ & $<0.001$ & $127(53.4)$ & $171(71.8)$ & $<0.001$ & $100(52.9)$ & $110(58.2)$ & 0.288 \\
\hline $\begin{array}{l}\text { Time to } \\
\text { discontinuation } \\
\text { in days, mean }(\mathrm{SD})\end{array}$ & $185(113)$ & $162(114)$ & 0.091 & $185(113)$ & $153(105)$ & 0.014 & $180(111)$ & $160(114)$ & 0.196 \\
\hline \multicolumn{10}{|l|}{ Sensitivity analysis $1^{\mathrm{b}}$} \\
\hline $\begin{array}{l}\text { Duration of } \\
\text { persistence in days, } \\
\text { mean (SD) }\end{array}$ & $252(128)$ & $196(130)$ & $<0.001$ & $252(128)$ & $193(127)$ & $<0.001$ & $253(127)$ & $216(140)$ & 0.024 \\
\hline $\begin{array}{l}\text { Discontinuation } \\
\text { of index } \\
\text { medication, } n(\%)\end{array}$ & $138(58.0)$ & $186(78.2)$ & $<0.001$ & $138(58.0)$ & $185(77.7)$ & $<0.001$ & $108(57.1)$ & $125(66.1)$ & 0.070 \\
\hline \multicolumn{10}{|l|}{ Sensitivity analysis $2^{\mathrm{c}}$} \\
\hline $\begin{array}{l}\text { Duration of } \\
\text { persistence in days, } \\
\text { mean (SD) }\end{array}$ & $253(128)$ & $235(129)$ & 0.006 & $253(128)$ & $248(129)$ & 0.210 & $254(127)$ & $274(122)$ & 0.219 \\
\hline $\begin{array}{l}\text { Discontinuation } \\
\text { of index } \\
\text { medication, } n(\%)\end{array}$ & $137(57.6)$ & $170(71.4)$ & 0.003 & $137(57.6)$ & $154(64.7)$ & 0.105 & $108(57.1)$ & $99(52.4)$ & 0.336 \\
\hline
\end{tabular}

Log rank test was used for continuous variables and conditional logistic regression for categorical variables

$I L-12 / 23 i$ interleukin-12/23 inhibitor, $I L-17 i$ interleukin-17 inhibitor, $S D$ standard deviation, $T N F i$ tumor necrosis factor inhibitor, tsDMARD targeted synthetic disease-modifying antirheumatic drug

a Allowable gap definition: 1.5 times maintenance days' supply of the index medication from the end of days' supply of one fill to the date of next fill

b Allowable gap definition: 1 times maintenance days' supply of the index medication from the end of days' supply of one fill to the date of next fill

c Allowable gap definition: Fixed allowable gap of 90 days from the end of days supply of one fill to the date of the next fill 

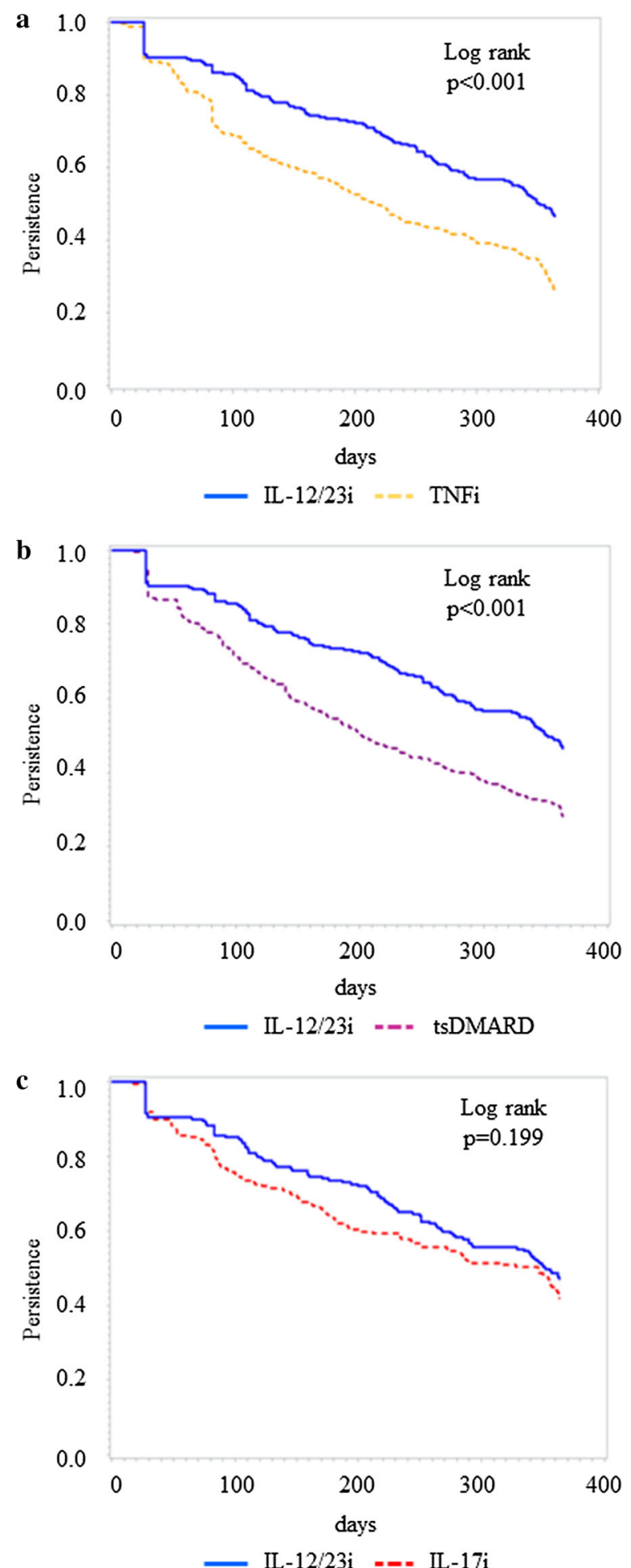

Fig. 2 Kaplan-Meier curves of the duration of persistence during the 12-month follow-up period of matched study cohorts: a IL-12/23i versus TNFi, b IL-12/23i versus tsDMARD, and c IL-12/23i versus IL-17i overall discontinuation rate within 2 years of initiation was approximately 80\% [9].

PsA represents a considerable clinical and economic burden in the US. In a study of 35,061 matched pairs of patients with PsA and without PsA or psoriasis in the US, it was reported that those with PsA utilized medical services, including inpatient and outpatient services, to a significantly greater extent than those without the disease and incurred US $\$ 18,482$ adjusted higher medical costs per patient per year [12]. With the understanding that early diagnosis and effective treatment benefit the long-term outcomes of individuals with PsA [13-15], and that improved adherence to PsA treatments reduces healthcare costs $[16,17]$, persistence and adherence should be considered when treatment strategies are formulated.

\section{Limitations}

The findings of this study should be interpreted from the perspective of the following limitations. Firstly, inherent to retrospective claims database analyses, administrative healthcare claims data are collected for the purpose of facilitating payment for healthcare services and, therefore, clinician-verified diagnoses and specific information regarding disease activity and PsA phenotypes are not available. Consequently, we were unable to assess the association between disease severity, PsA phenotypes, and treatment patterns. Pharmacy claims data do not necessarily indicate the actual administration of the medication. Generic (paid out-ofpocket) or over-the-counter medications are additionally not captured to a significant extent in claims data sources, and therefore usage of these medications, such as over-the-counter NSAIDs, could not be evaluated in this study. The reasons for treatment discontinuation could not be determined in this study, since the data source was administrative healthcare claims, and therefore this study was not designed to assess factors affecting treatment selection or predictors of persistence. Potentially, discontinuation at the end of the followup period was captured more frequently for the targeted immune modulators with shorter 


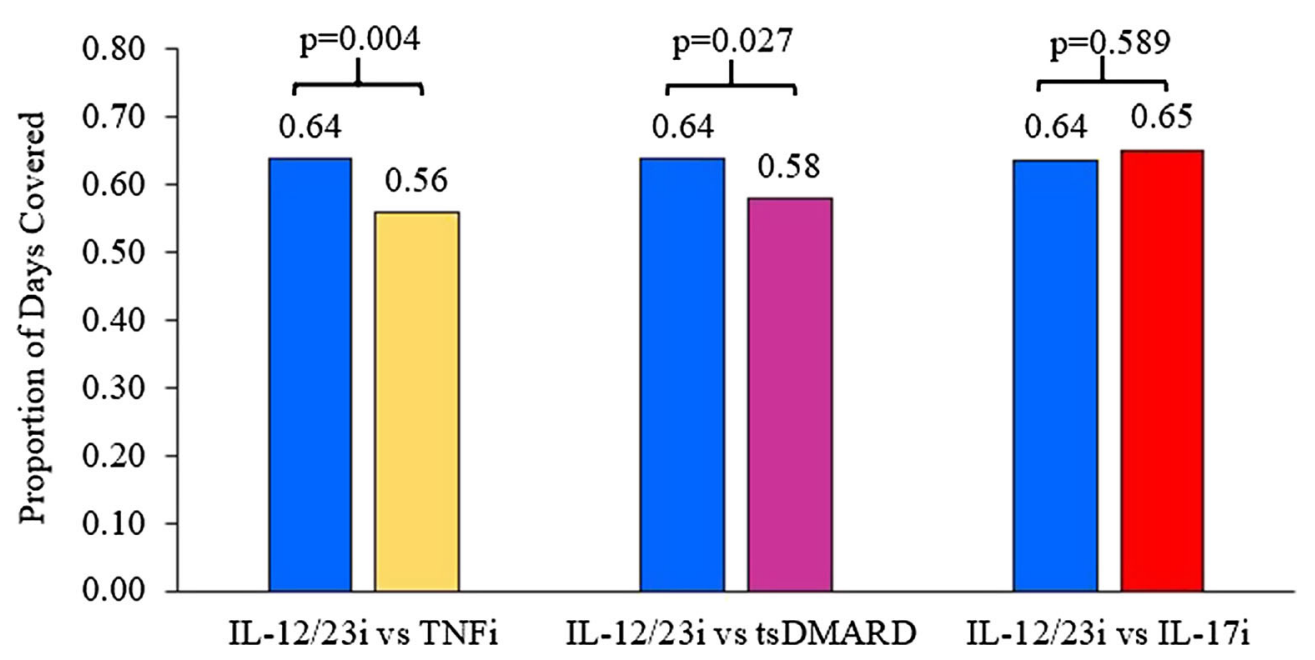

Fig. 3 Treatment adherence during the 12-month follow-up period of matched study cohorts. $P$-values were determined by paired $t$ test

versus longer treatment gap definitions, thus the differences in discontinuation and persistence between IL12/23i and other medications with shorter dosing intervals may be overestimated within a fixed 12-month follow-up period. This study only included PsA patients covered by commercial or Medicare supplemental insurance plans in the US; therefore, the results may not generalize well to patients with other insurance types, such as standard Medicare or Medicaid, nor to patients with PsA residing in other countries with various healthcare systems. Lastly, treatment options for PsA have evolved over time and patients included in this study may have had different treatments available to them depending on their study period.

\section{CONCLUSIONS}

In this real-world study of biologic-naïve commercially insured patients with PsA, those who initiated an IL-12/23i had longer persistence, a lower discontinuation rate, and higher treatment adherence compared to patients who initiated a TNFi or tsDMARD during 1 year of follow-up; treatment outcomes were comparable between patients initiating an IL-12/23i and an IL-17i. Further studies of long-term treatment patterns with targeted immune modulators and reasons for non-persistence and non-adherence may contribute to advancements in treatment strategies for PsA.

\section{ACKNOWLEDGEMENTS}

Funding. This research, preparation of this manuscript, rapid service/ open access fees and article processing charges were sponsored by Janssen Scientific Affairs, LLC.

Medical Writing and/or Editorial Assistance. The authors would like to thank Jay Lin and Melissa Lingohr-Smith of Novosys Health for their writing and editorial contributions to this manuscript and acknowledge that these contributions were supported by Janssen Scientific Affairs, LLC. Additionally, the authors would like to thank Shubham Shrivastava of $\mathrm{Mu}$ Sigma Business Solutions Pvt. Ltd. (Bengaluru, India) for programming support, which was also funded by Janssen Scientific Affairs, LLC.

Authorship. All named authors meet the International Committee of Medical Journal Editors (ICMJE) criteria for authorship for this article, take responsibility for the integrity of the work as a whole, and have given their approval for this version to be published. 
Disclosures. Jessica A Walsh has received grants and/or served as a consultant for Pfizer, AbbVie, Novartis, Lilly, and UCB. Qian Cai, Iris Lin, Christopher D. Pericone, and Soumya D. Chakravarty are employees of Janssen Scientific Affairs, LLC, and stockholders of Johnson \& Johnson, of which Janssen Scientific Affairs, LLC is a wholly owned subsidiary.

Compliance with Ethics Guidelines. The data sources used for this study were comprised of administrative healthcare claims that were deidentified and certified to be fully compliant with the Health Insurance Portability and Accountability Act patient confidentiality requirements. Institutional review board approval to conduct this study was not required because the study used only deidentified patient records and did not involve the collection, use, or transmittal of individually identifiable data.

Data Availability. All data generated or analyzed during this study are included in this published article or as supplementary information files.

Open Access. This article is licensed under a Creative Commons Attribution-NonCommercial 4.0 International License, which permits any non-commercial use, sharing, adaptation, distribution and reproduction in any medium or format, as long as you give appropriate credit to the original author(s) and the source, provide a link to the Creative Commons licence, and indicate if changes were made. The images or other third party material in this article are included in the article's Creative Commons licence, unless indicated otherwise in a credit line to the material. If material is not included in the article's Creative Commons licence and your intended use is not permitted by statutory regulation or exceeds the permitted use, you will need to obtain permission directly from the copyright holder. To view a copy of this licence, visit http://creativecommons.org/licenses/by$\mathrm{nc} / 4.0 /$.

\section{REFERENCES}

1. Cantini F, Niccoli L, Nannini C, Kaloudi O, Bertoni $\mathrm{M}$, Cassarà E. Psoriatic arthritis: a systematic review. Int J Rheum Dis. 2010;13:300-17.

2. Singh J, Guyatt G, Ogdie A, et al. 2018 American College of Rheumatology/National Psoriasis Foundation guideline for the treatment of psoriatic arthritis. Arthritis Rheumatol. 2019;71:5-32.

3. Ogdie A, Weiss P. The epidemiology of psoriatic arthritis. Rheum Dis Clin N Am. 2015;41:545-68.

4. Alinaghi F, Calov M, Kristensen LE, et al. Prevalence of psoriatic arthritis in patients with psoriasis: a systematic review and meta-analysis of observational and clinical studies. J Am Acad Dermatol. 2019;80(251-265):e19.

5. Feldman SR, Pelletier CL, Wilson KL, et al. Treatment patterns and costs among biologic-naive patients initiating apremilast or biologics for psoriatic arthritis. J Comp Eff Res. 2019;8:699-709.

6. Walsh JA, Adejoro O, Chastek B, Palmer JB, Hur P. Treatment patterns among patients with psoriatic arthritis treated with a biologic in the United States: descriptive analyses from an administrative claims database. J Manag Care Spec Pharm. 2018;24: 623-31.

7. Sikka R, Xia F, Aubert RE. Estimating medication persistency using administrative claims data. Am J Manag Care. 2005;11:449-57.

8. Oelke KR, Chabenoit O, Majjhoo AQ, Gray S, Higgins $\mathrm{K}$, Hur P. Persistence and adherence of biologics in US patients with psoriatic arthritis: analyses from a claims database. J Comp Eff Res. 2019;8:607-21.

9. Walsh JA, Cai Q, Lin I, Fitzgerald T, Pericone CD, Chakravary SD. Real-world 2-year treatment patterns among patients with psoriatic arthritis treated with injectable biologic therapies. Curr Med Res Opin. 2020;36:1245-52.

10. Wu JJ, Pelletier C, Ung B, Tian M. Treatment patterns and healthcare costs among biologic-naive patients initiating apremilast or biologics for the treatment of psoriatic arthritis: results from a US claims analysis. Curr Med Res Opin. 2020;36: 169-76.

11. Zhu B, Edson-Heredia E, Gatz JL, Guo J, Shuler CL. Treatment patterns and health care costs for patients with psoriatic arthritis on biologic therapy: a retrospective cohort study. Clin Ther. 2013;35: 1376-85. 
12. Merola JF, Herrera V, Palmer JB. Direct healthcare costs and comorbidity burden among patients with psoriatic arthritis in the USA. Clin Rheumatol. 2018;37:2751-61.

13. Gladman D. Early psoriatic arthritis. Rheum Dis Clin N Am. 2012;38:373-86.

14. Gladman D, Thavaneswaran A, Chandran V, Cook R. Do patients with psoriatic arthritis who present early fare better than those presenting later in the disease? Ann Rheum Dis. 2011;70:2152-4.

15. Kirkham B, de Vlam K, Li W, et al. Early treatment of psoriatic arthritis is associated with improved patient-reported outcomes: findings from the etanercept PRESTA trial. Clin Exp Rheumatol. 2015;33:11-9.

16. Brixner D, Rubin DT, Mease P, et al. Patient support program increased medication adherence with lower total health care costs despite increased drug spending. J Manag Care Spec Pharm. 2019;25: 770-9.

17. Pasma A, Schenk C, Timman R, et al. Does nonadherence to DMARDs influence hospital-related healthcare costs for early arthritis in the first year of treatment. PLoS ONE. 2017;12:e0171070. 